\title{
The Effect of Switching the Order of Experimental Teaching in the Study of Simple Gravity Pendulum - A Study with Junior High-school Learners
}

\author{
https://doi.org/10.3991/ijet.v12i03.6492 \\ Charilaos A. Tsihouridis \\ University of Thessaly, Department of Special Education, Volos, Greece \\ hatsihour@uth.gr \\ Dennis Vavougios \\ University of Thessaly, Department of Special Education, Volos, Greece \\ dvavou@uth.gr \\ George S. Ioannidis \\ University of Patras, The Science Laboratory, Patras, Greece \\ gsioanni@upatras.gr
}

\begin{abstract}
The present study focuses on the educational value of lab work while teaching and learning Physics. Specifically, it investigates and compares the learning outcomes between three different experimental groups, in the study of the Simple Gravity Pendulum in the lower secondary school, using a sample of 61 students aged 14-15. The first group comprising 25 students practiced first on virtual and then on real lab, while the second group of 24, first on real and then on virtual lab (change of order in the tasks).An additional third group, involving 12 students, used sensors and data loggers during experimental practice. The educationally optimum order of use of such labs is investigated herein. The learners exploited the capabilities of the lab equipment, in that they themselves designed, constructed, and analysed the simple gravity pendulum. The focus in the teaching and learning of the pendulum was on examining subject relevance in the context of everyday applications, the independency of the period from the mass of the bob, or the amplitude, and the dependence of the period from the pendulum length, and the local acceleration of gravity. The research tools used were a stabilised questionnaire, with 16 closed-type questions and 7 questions asking for a justifying answer, in addition to a semi-structured interview. Data were taken and were appropriately analysed and compared, and conclusions are presented herein. The results confirmed that concerning some teaching objectives, learners' understanding is positively affected by the order the real and the virtual labs are used in teaching. This result applies when addressing this age-group, and when teaching the simple gravity pendulum.
\end{abstract}

Keywords-Science teaching, Real experiments, Virtual experiments, comparative study, simple gravity pendulum 


\section{Introduction}

Even though the study of the simple gravity pendulum is included in the majority of school curricula of physics worldwide, learners' perceptions about it are relatively poor [1]. According to literature reviews, research findings regarding students' perceptions and/or misconceptions about the apparatus and the associated observations, mainly fall into two categories. The first one is about research that relates to simple gravity pendulums, which students observe in a natural environment forming a mathematical model of a pendulum. In this category, it is the Newtonian conceptual framework that prevails, and students' perceptions refer to the period or frequency dependency of the simple gravity pendulum, the width of hovering, the weight of the bob, its length and their combinations $[2,3,4,5,6,7,8]$. The second category refers to themethodology used by researchers to examine the accuracy of the mathematical model regarding its ability to simulate and adequately describe the observed natural behaviour of the pendulum [9,10], [4], [11,12]. It seems that students' misconceptions about the pendulum are significantly affected by their perceptions as regards their ability to recognise the variables and the checking of conditions [4]. Therefore, whatever change there may appear in the first one, should also include the second ones as well [10].

Finally, according to literature reviews, there is just one study that refers to students' cultural perceptions regarding the pendulum [7]. This fact demonstrates the acute mismatch between its profound role in physics $[13,14,15,16,17]$ and science in general, and (on the other hand) its place in school curricula as a cultural feature [18]. During the past years, a large number of research effort on Science teaching has been reported. The main research topic seems to be the investigation of students' ideas (or misrepresentations), the study of students' reasoning and comprehension, and the methods proposed for overcoming any intellectual difficulties to conquest scientific thinking. One of the most important research results is the ascertainment that students use alternative models, with the help of which they mediate and try to comprehend all science phenomena and their everydayapplications. These so-called"alternative ideas", often remain unchanged or partly modified, even after many years of repeated teaching at a theoretical or experimental level, throughout formal education. To this end, to detect and confront them is of great interest to Science Education researchers, and especially so for such important physical phenomena, relevant for both Science and everyday life.

\section{Rationale for the Present Study}

Experiments play a dominant role in physics, and also in our attempt to understand the processes of physical phenomena in our world [19]. Studies have shown that school experiments affect and enhance knowledge acquisition more than traditional chalk-and-blackboard teaching. Teaching strategies incorporating experiments are considered the most important educational tools in the science classroom, especially when teaching difficult or abstract concepts [19]. Their role is to link theory with 
practice, especially for those students acquiring experimental skills, and enhance their exposure to scientific thinking and their consequently help their cognitive development. Experiments can be (a) real or (b) virtual or (c) performed with the use of sensors and data loggers.

Studies have shown that when experiments are appropriately designed, and engage learners in interaction and cooperation, they yield positive cognitive results. Moreover, research findings conducted between 1987 onwards, testing the educational use of real and virtual laboratories, have shown that the overall effect of such interventions was didactically similar when comparing real and virtual laboratories. Furthermore, combining both types was considered even more successful. [20, 21, 22]. Keeping the aforementioned points in mind, and while appreciating the usefulness of both real and virtual labs in the teaching and learning process, it was decided to test the educational effect when switching the order the labs were performed, in class. What happens educationally when we first perform the virtual experiment and then the real one, and how does this compare with the opposite order of events, i.e. doing the real one first?Furthermore, when the experimental setup is enhanced by the use of sensors and data loggers, which is the optimum order to perform these experiments? Which educational planning yields the best educational effect? Which educational planning yields the best results? The validity of the present test is further enhanced by the similarity in the design of the real and the virtual lab exercises. Indeed, real and virtual labsare not only mutually compatible but also similar as, being designed in parallel, they form part of the very same unit of school-lab experiments. Systematic errors were further reduced in this study by the fact that the teaching was supervised by the same researcher in all 3 (broadly similar) experimental groups.

\section{The Research}

\subsection{Research questions}

Themainresearchquestion addressed hereinwas the investigation of the optimum teaching order. Which of the three - first therealand then the virtual lab, orfirst the virtualand then the reallab, or perhaps the use of sensors and data loggers- canbetter improvelearning? Which method would yield the best resultsintheteaching of the basicconceptsconcerning the simple gravity pendulum?As such, we have identified and tested the following aspects: Relevance and everyday applications, independence of pendulum frequency from the mass of the bob, dependence from the pendulum length, the local acceleration of gravity, and the ever slight dependency of the natural frequency from the amplitude (i.e. the swing).

\subsection{The Sample}

The sample consisted of three groups making a total of 61 Junior High School students, aged 14-15. Specifically, 25 learners worked on experiments progressing form virtual to real labs (group-1), another 24 learners with experiments starting from real 
and moving to virtual labs (group-2), and 12 more learners using sensors and data loggers (group-3). The learners exploited the capabilities of the lab equipment in order to design, create, and analyse the simple gravity pendulum.

\subsection{Research tools}

The study used both quantitative and qualitative research methods. The latter was used to provide the researchers with a clearer picture of any hitherto unsuspected educational research issues, via direct talk with the students, and utilised for research validation purposes. The research tool was a stabilised test with 16 closed-type questions of and 7 questions that asked a justifying answer, and in additiona semistructured interview. The aforementioned test was verified regarding its validity and reliability during a pilot-phase testing. The teaching objectives of the specific questionnaire used are presented grouped in various categories, in Table 1 below:

Table 1. Categories of Teaching Objectives for the Subject Taught

\begin{tabular}{|l|c|l|}
\hline \multicolumn{1}{|c|}{$\begin{array}{c}\text { Categories of teaching objectives for } \\
\text { subject taught }\end{array}$} & $\begin{array}{c}\text { Question } \\
\text { Number }\end{array}$ & \multicolumn{1}{|c|}{ Teaching objectives } \\
\hline $\begin{array}{l}\text { O1. Relevance \& everyday applications of } \\
\text { simple pendulum }\end{array}$ & $1,2,3,4$ & $\begin{array}{l}\text { To understand the usefulness and everyday } \\
\text { applications of simple pendulum }\end{array}$ \\
\hline $\begin{array}{l}\text { O2. Dependency of period on the pendu- } \\
\text { lum length }\end{array}$ & 7,14 & $\begin{array}{l}\text { To understand the relationship between } \\
\text { period and pendulum length }\end{array}$ \\
\hline $\begin{array}{l}\text { O3. Independency of period on the mass of } \\
\text { the bob }\end{array}$ & $5,9,11,15$ & $\begin{array}{l}\text { To understand the relationship between } \\
\text { period and mass of the bob }\end{array}$ \\
\hline $\begin{array}{l}\text { O4. Dependency of period on local accel- } \\
\text { eration of gravity }\end{array}$ & $12,13,16$ & $\begin{array}{l}\text { To understand the relationship between } \\
\text { length and the local acceleration of gravity }\end{array}$ \\
\hline $\begin{array}{l}\text { O5. Independency of period from the } \\
\text { amplitude }\end{array}$ & 6,8 & $\begin{array}{l}\text { To understand the relationship between } \\
\text { period and amplitude of the swing }\end{array}$ \\
\hline
\end{tabular}

\subsection{The purpose of the research}

The purpose of the present study is to investigate the educational effect when switching the teaching-order when using virtual and real labs, as well aswhen experimenting with sensors and data loggers, while studying the simple gravity pendulum. More particularly, the aim was to investigate the extent to which a different order in the use of labs (i.e. first virtual and then real,versus using first the real and then the virtual lab) gives the best results in terms of conceptual understanding of the basic concepts concerningthe simple gravity pendulum on 14-15 year-olds. An additional aim concerns the question of whether any progress of conceptual understanding differs when students practice on real laboratory using sensors and ICT, albeit combined with adequate theoretical explanation. For this purpose, a comparative study was conducted between different orderings (time-wise) of lab-type usage, in order to determine the effectiveness of switching the order of Lab-teaching, using whichever method. 


\subsection{Research stages}

Theresearch took place in three successive phases of 6 teaching hours, with an additional fourth phase of one hour (conducted after a month) used in order to detect any late changes of learners' ideas, regarding the simple gravity pendulum.

Particularly, during the first phase (1 hour), learners' alternative ideas were detected with a test (pre-test), which was appropriately adapted from that directed to older students, to the learner's level of comprehension. The second phase (4 hours) started with learners' familiarisation with the lab equipment to be used, and some general information provided to the learners concerning the subject of simple gravity pendulum. The basic instructive tool used was a worksheet following the principles of inquiry-based learning, containing all activities to be completed, and the instructions to be followed so as learners shifted from virtual to real labs or vice versa, or alternatively used sensors and data loggers. During the third and last 1-hour phase of the research (conducted three weeks later), learners a post-test (which was the same text as the pre-test) in order to detect any changes in their initial ideas regarding gravity pendulums.

Analytically:

$1^{\text {st }}$ phase of intervention (1-hour):The students of the three groups were given a questionnaire to answer (as a pre-test) with the help of which their preliminary ideas regarding the subject taught were recorded. Interviews and discussions followed, to probe students' opinions and ideas, truly latent to them as they often are, and consequently obscured from us as they lamentably often remain.

$2^{\text {nd }}$ phase of intervention (4-hours): The second phase started with learners' familiarisation with the lab equipment to be used, while providing some preliminary information concerning gravity pendulums.

$3^{\text {rd }}$ phase of intervention (1-hour):Semi-conducted interviews, and open discussions were conducted. This was done to probe even further students' (hopefully improved) opinions and ideas, albeitstill rather latent to them as they might remain. Subliminally presented stimuli were often used to that effect, as a means of communication.

$4^{\text {th }}$ phase of intervention (1-hour):Three weeks after the conclusion of the aforementioned teaching,the samelearnerswereaskedtocomplete thesame initialquestionnaire, so as todetectany permanent changein their ideas regardingthe simple gravity pendulum.

\section{$4 \quad$ Results}

\subsection{Method of processing the experimental data}

In the present study, the broadest possible definition of the term "assessment" is adopted (i.e. estimating, testing, measuring, rating). Specifically, assessment is "the process of evaluating the effectiveness of a particular sequence of instructional activi- 
ties when the sequence is completed" [23]. This can be achieved, asaforementioned, with a proper tool that allows the classification of what is being assessed in at least two hierarchical levels, focusing on the variable of interest, despite the numerical expression of the result. The numerical expression of the result from a diagnostic test may well lead to the illusion of accuracy and objectivity of the evaluation. But no one is ever able to assure us that every question of a perfectly balanced and objective test has exactly the same value and the same importance as the others.

\subsection{Statistical analysis-data analysis}

The use of the appropriate checking criterion (parametric or not) between research hypotheses depends mainly on the plan of the research, the commitment of the level of data, and the type of the indices of the measurement of the variables. To analyse the data obtained presently, the IBM-SPSS statistical package was used, and an ANOVA-test for independent and a t-test criterion for dependent samples were performed. For the purpose of the present study, the level of significance was set at $5 \%$. The research hypotheses are:

H0: Null hypothesis: The participant groups of learners display the same performance after the teaching intervention.

H1: Alternative hypothesis: The participant groups of learners have display different performances between them, after the teaching intervention.

It should be noted that, in H1, there is no intrinsic attempt to predict which group displays the best or worst performance. Therefore, a two-sided checking of hypotheses is formulated. The results are presented below.

\subsection{Discussion of the results}

It is reminded that the participant groups were three, group G1 consisting of 25 learners working from virtual to real environment, group G2 comprising 24 students working from real to virtual environment, while a further 12 learners used sensors and data loggers (G3). The comparison process of the three groups' performance entails four basic stages of checking. (a) Checking per group and between groups, regarding pre and post instructive aim O1. (b) As above but for aim O2. (c) As above but now for aim O3. (d) As above but for aim O4, (e) checking per group and between groups in the pre and post instructive as above but concerning aim O5, and (f) checking per group and between groups as regards their total performance.

Checking groups G1, G2 and G3 before the teaching intervention (Pre-testing) for all individual teaching objectives: Table 2 represents the ANOVA - test of independent samples. 
Paper-The Effect of Switching the Order of Experimental Teaching in the Study of Simple Gravity...

Table 2. Results ANOVA-test for independent sambles at pre-testing level for all individual teaching objectives

\begin{tabular}{|c|c|c|c|c|c|}
\hline & & df & Mean Square & $\mathbf{F}$ & Sig. \\
\hline \multirow{2}{*}{ Usefulness - Pre-test } & Between Groups & 2 & 215.429 & .425 & .656 \\
\hline & Total & 60 & & & \\
\hline \multirow{2}{*}{ T vs L Pre-test } & Between Groups & 2 & 478.108 & .321 & .727 \\
\hline & Total & 60 & & & \\
\hline \multirow{3}{*}{ T vs W Pre-test } & Between Groups & 2 & 256.754 & .450 & .640 \\
\hline & Within Groups & 58 & 570.923 & & \\
\hline & Total & 60 & & & \\
\hline \multirow{2}{*}{ T vs g Pre-test } & Between Groups & 2 & 385.935 & .382 & .684 \\
\hline & Total & 60 & & & \\
\hline \multirow{2}{*}{ T vs $\theta$ Pre-test } & Between Groups & 2 & 510.041 & .483 & .620 \\
\hline & Total & 60 & & & \\
\hline
\end{tabular}

This is based on the ANOVA-test,obtained for all individual teaching objectives which correspond to a (pre-determined) non-significant statistical $(p>0.05)$ result. This leads to the acceptance of the null hypothesis, meaning that the performance of learners in group G1 does not differ from that of the learners in group G2,or those in group $\mathrm{G} 3$ before the teaching intervention $\left(\mu_{01 \mathrm{TOTAL}}=\mu_{02 \mathrm{TOTAL}}=\mu_{03 \mathrm{TOTAL}}\right)$, for each individual teaching objective. One can therefore proceed with the rest of the comparisons.

We can reach the same conclusion using a chart (error chart1) with the intervals of confidences et at 95\%ofthemeanof each group's performance (see Figure 1).

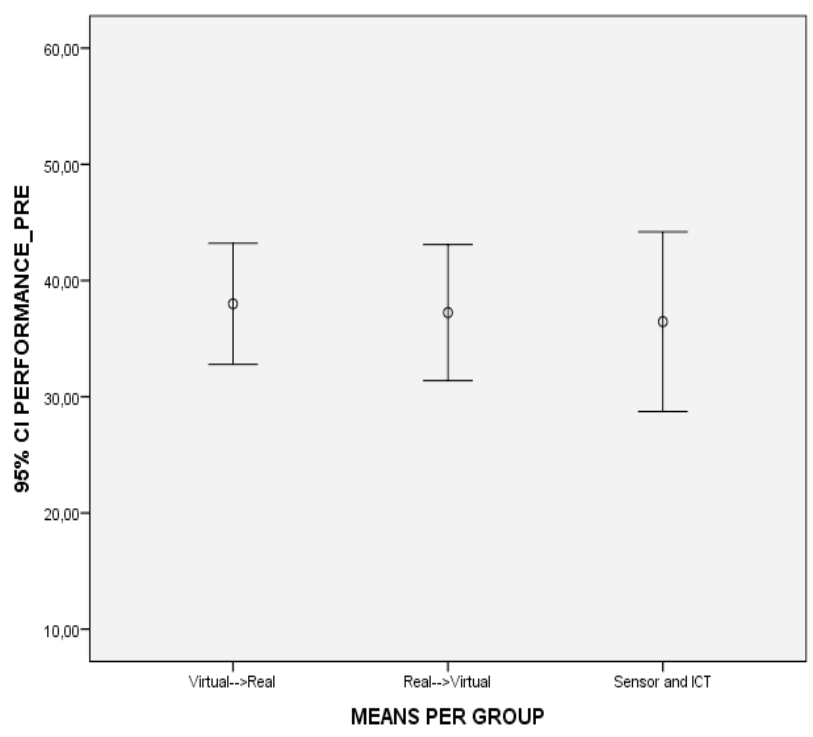

Fig. 1. Error chart for the participant groups in the research at pre-test 
From the above diagrams, one can deduce that there is no statistically significant difference between groups at the pre- test stage, as the corresponding overlaps are larger than half of the mean error margin. This means that, since the two groups were indistinguishable, all further testing is valid.

Checking groups G1, G2 and G3 after the teaching intervention (Post-testing) for all individual teaching objectives: Table 3 represents the ANOVA - test of independent samples.

Table 3. The table with the descriptive indexes of the dependent variable (performance) at the three conditions of the independent variable at post-testing

\begin{tabular}{|l|c|c|c|c|}
\hline & N & Mean & Std. Deviation & Std. Error \\
\hline G1: Virtual $\rightarrow$ Real & 25 & 71.75 & 9.73 & 1.94 \\
\hline G2: Real $\rightarrow$ Virtual & 24 & 78.12 & 10.42 & 2.12 \\
\hline G3: Sensor and ICT & 12 & 64.06 & 14.62 & 4.22 \\
\hline Total & 61 & 72.74 & 12.07 & 1.54 \\
\hline
\end{tabular}

After the intervention the results of the post-test revealed that the learners who started with the real lab and continued with the virtual one achieved better results $(78.12 \% \pm 10.42 \%)$ than either those who began with the virtual and continued with the real laboratory activities $(71.75 \% \pm 9.73 \%)$ or those that dealt with the sensors and the data loggers $(64.06 \% \pm 14.62 \%)$.

Table 4. The overall table oft he variance at post-testing

\begin{tabular}{|l|c|c|c|c|}
\hline & df & Mean Square & F & Sig. \\
\hline Between Groups * & 2 & 812.023 & 6.607 & .003 \\
\hline Within Groups & 58 & 122.905 & & \\
\hline Total & 60 & & & \\
\hline
\end{tabular}

The ANOVA-test shows significant statistical results $[(\mathrm{F}(2,60)=6,607, \mathrm{p}=0,003]$. This result indicates that this differentiation should be investigated further to determine between which experimental groups this occurred. 
Paper-The Effect of Switching the Order of Experimental Teaching in the Study of Simple Gravity...

Table 5. Multiple comparisons for the dependent variable performace post-test the results of applying the criterionTukey HSD tot he three conditions oft he Independent variable

Dependent Variable: PERFORMANCE POST-TEST

\begin{tabular}{|l|l|c|c|c|}
\multicolumn{5}{|c}{ Tukey's Honest Significant Difference (HSD) test } \\
\hline \multirow{2}{*}{ (I) MEANS PER GROUP } & \multicolumn{1}{|c|}{$\begin{array}{c}\text { (J) MEANS PER } \\
\text { GROUP }\end{array}$} & Mean Difference (I-J) & Std. Error & Sig. \\
\hline \multirow{2}{*}{ G1: Virtual--> Real } & Real $\rightarrow$ Virtual & -6.375 & 3.168 & .118 \\
\cline { 2 - 5 } & Sensor and ICT & 7.687 & 3.893 & .128 \\
\hline \multirow{2}{*}{ G2: Real-->Virtual } & Virtual $\rightarrow$ Real & 6.375 & 3.168 & .118 \\
\cline { 2 - 5 } & Sensor and ICT & $\mathbf{1 4 . 0 6 2}^{*}$ & $\mathbf{3 . 9 1 9}$ & $\mathbf{. 0 0 2}$ \\
\hline \multirow{2}{*}{ G3: Sensor and ICT } & Virtual $\rightarrow$ Real & -7.687 & 3.893 & .128 \\
\cline { 2 - 5 } & Real $\rightarrow$ Virtual & $\mathbf{- 1 4 . 0 6 2}^{*}$ & $\mathbf{3 . 9 1 9}$ & $\mathbf{. 0 0 2}$ \\
\hline
\end{tabular}

The results showed that there is a statistically significant difference between the groups, and the use of the criterion Tukey HSD (Post-Hoc Multiple Comparisons) showed that the statistically significant difference is to be found between the groups G2 (Real $\rightarrow$ Virtual) and G3 (Sensors and Data Loggers) $[\mathrm{MD}(\mathrm{I}-\mathrm{J})=14,06$, $\mathrm{p}=0,002)])$.

Table 6. Results of anova-test fort he independent sambles at post-testing for all individual teaching objectives

\begin{tabular}{|l|l|l|l|l|}
\hline \multicolumn{2}{|c|}{} & \multicolumn{1}{|c|}{ df } & \multicolumn{1}{c|}{ F } & Sig. \\
\hline $\begin{array}{l}\text { Usefulness - } \\
\text { Applications Post-test }\end{array}$ & Between Groups & 2 & 1.632 & .204 \\
\hline & Total & 60 & & \\
\hline \multirow{2}{*}{ T vs L Post-test } & Between Groups & 2 & 1.339 & .270 \\
\hline & Total & 60 & & \\
\hline \multirow{2}{*}{ T vs W Post-test } & Between Groups & $\mathbf{2}$ & $\mathbf{5 . 2 3 1}$ & $\mathbf{. 0 0 8}$ \\
\hline & Total & $\mathbf{6 0}$ & & \\
\hline \multirow{2}{*}{ T vs g Post-test } & Between Groups & 2 & .524 & .595 \\
\hline & Total & 60 & & \\
\hline \multirow{2}{*}{ T vs $\theta$ Post-test } & Between Groups & 2 & .276 & .760 \\
\hline & Total & 60 & & \\
\hline
\end{tabular}


Paper-The Effect of Switching the Order of Experimental Teaching in the Study of Simple Gravity...

Table 7. Multiple comparisons for the dependent variable performance post-test the results of applying the criterion Tukey HSD, for all individual teaching objectives.

Tukey's Honest Significant Difference (HSD) test

\begin{tabular}{|c|c|c|c|c|c|}
\hline Dependent Variable & $\begin{array}{l}\text { (I) MEANS PER } \\
\text { GROUP }\end{array}$ & $\begin{array}{l}\text { (J) MEANS PER } \\
\text { GROUP }\end{array}$ & $\begin{array}{l}\text { Mean Differ- } \\
\text { ence (I-J) }\end{array}$ & Std. Error & Sig. \\
\hline \multirow{6}{*}{$\begin{array}{l}\text { Usefulness - Applica- } \\
\text { tions Post-test }\end{array}$} & \multirow{2}{*}{ Virtual $\rightarrow$ Real } & Real $\rightarrow$ Virtual & -3.291 & 5.136 & .798 \\
\hline & & Sensor and ICT & 8.166 & 6.313 & .404 \\
\hline & \multirow{2}{*}{ Real $\rightarrow$ Virtual } & Virtual $\rightarrow$ Real & 3.291 & 5.137 & .798 \\
\hline & & Sensor and ICT & 11.458 & 6.355 & .178 \\
\hline & \multirow{2}{*}{ Sensor and ICT } & Virtual $\rightarrow$ Real & -8.166 & 6.312 & .404 \\
\hline & & Real $\rightarrow$ Virtual & -11.458 & 6.355 & .178 \\
\hline \multirow{6}{*}{ T vs L Post-test } & \multirow{2}{*}{ Virtual $\rightarrow$ Real } & Real $\rightarrow$ Virtual & -1.000 & 8.781 & .993 \\
\hline & & Sensor and ICT & 15.666 & 10.791 & .322 \\
\hline & \multirow{2}{*}{ Real $\rightarrow$ Virtual } & Virtual $\rightarrow$ Real & 1.000 & 8.781 & .993 \\
\hline & & Sensor and ICT & 16.666 & 10.864 & .283 \\
\hline & \multirow{2}{*}{ Sensor and ICT } & Virtual $\rightarrow$ Real & -15.666 & 10.791 & .322 \\
\hline & & Real $\rightarrow$ Virtual & -16.666 & 10.864 & .283 \\
\hline \multirow{6}{*}{ T vs W Post-test } & \multirow{2}{*}{ Virtual $\rightarrow$ Real } & Real $\rightarrow$ Virtual & $-14.416^{*}$ & 5.791 & .041 \\
\hline & & Sensor and ICT & 6.416 & 7.116 & .641 \\
\hline & \multirow{2}{*}{ Real $\rightarrow$ Virtual } & Virtual $\rightarrow$ Real & $14.416^{*}$ & 5.791 & .041 \\
\hline & & Sensor and ICT & $20.833^{*}$ & 7.164 & .014 \\
\hline & \multirow{2}{*}{ Sensor and ICT } & Virtual $\rightarrow$ Real & -6.416 & 7.116 & .641 \\
\hline & & Real $\rightarrow$ Virtual & $-20.833^{*}$ & 7.164 & .014 \\
\hline \multirow{6}{*}{ T vs g Post-test } & \multirow{2}{*}{ Virtual $\rightarrow$ Real } & Real $\rightarrow$ Virtual & -4.166 & 7.740 & .853 \\
\hline & & Sensor and ICT & 5.556 & 9.512 & .829 \\
\hline & \multirow{2}{*}{ Real $\rightarrow$ Virtual } & Virtual $\rightarrow$ Real & 4.166 & 7.740 & .853 \\
\hline & & Sensor and ICT & 9.723 & 9.576 & .570 \\
\hline & \multirow{2}{*}{ Sensor and ICT } & Virtual $\rightarrow$ Real & -5.556 & 9.512 & .829 \\
\hline & & Real $\rightarrow$ Virtual & -9.723 & 9.576 & .570 \\
\hline \multirow{6}{*}{ T vs $\theta$ Post-test } & \multirow{2}{*}{ Virtual $\rightarrow$ Real } & Real $\rightarrow$ Virtual & -4.666 & 9.485 & .875 \\
\hline & & Sensor and ICT & 3.666 & 11.656 & .947 \\
\hline & \multirow{2}{*}{ Real $\rightarrow$ Virtual } & Virtual $\rightarrow$ Real & 4.666 & 9.485 & .875 \\
\hline & & Sensor and ICT & 8.333 & 11.735 & .759 \\
\hline & \multirow{2}{*}{ Sensor and ICT } & Virtual $\rightarrow$ Real & -3.666 & 11.656 & .947 \\
\hline & & Real $\rightarrow$ Virtual & -8.333 & 11.735 & .759 \\
\hline
\end{tabular}

*. The mean difference is significant at the 0.05 level.

Further statistical analysis using the ANOVA-test of the results, showed a statistically significant difference at the instructive goal concerning the relation between period and the mass of the bob, i.e. $[(\mathrm{F}(2,60)=5,231, \mathrm{p}=0,008]$ between the groups. The use Tukey HSD criterion showed that there is statistical significance between groups G2 (Real $\rightarrow$ Virtual) and G1 (Virtual $\rightarrow$ Real),i.e. $[\mathrm{MD}(\mathrm{I}-\mathrm{J})=14,41, \mathrm{p}=0,041)]$ 
and also betweenG1 with G3 (Sensors and Data Loggers), i.e. [MD(I-J) $=20,83$, $\mathrm{p}=0,014)]$ ). This allows one to assume that the subsequent use of real lab first to virtual laboratory later has improved learning of the specific subject taught, and for this specific age group, when compared to either the group that worked in the reverse order of lab activities, or the one that used sensors and data loggers.

From the chart in Figure 2, one can support the view that there is a statistically significant difference between groups at post-test stage, as the corresponding overlaps are not bigger than half the mean of the average marginal error. This holds true except for instructive aim $\mathrm{O} 3$ (i.e. Independency of period from the mass of the bob) where there are overlaps are bigger than half the mean marginal error.All this allowsone to assume that the subsequent use of real lab firstand virtual laboratory laterleads to improved learning of the specific subject taught, always for this particular age group. This is in comparison to both the group that worked in the reverse order of lab activities, or from group G3that used sensors and data loggers. It is worth mentioning however, that during the informal discussions with the learners, their excitement and enthusiasm was clearly apparent for the total procedure. Reasons given included the ability to switch from one type of lab to the other with relative ease, given that everything was provided for in the mobile-lab environment. As both types of lab were included in it and they did look similar to each other, no time was wasted in shifting from the one to the other type.

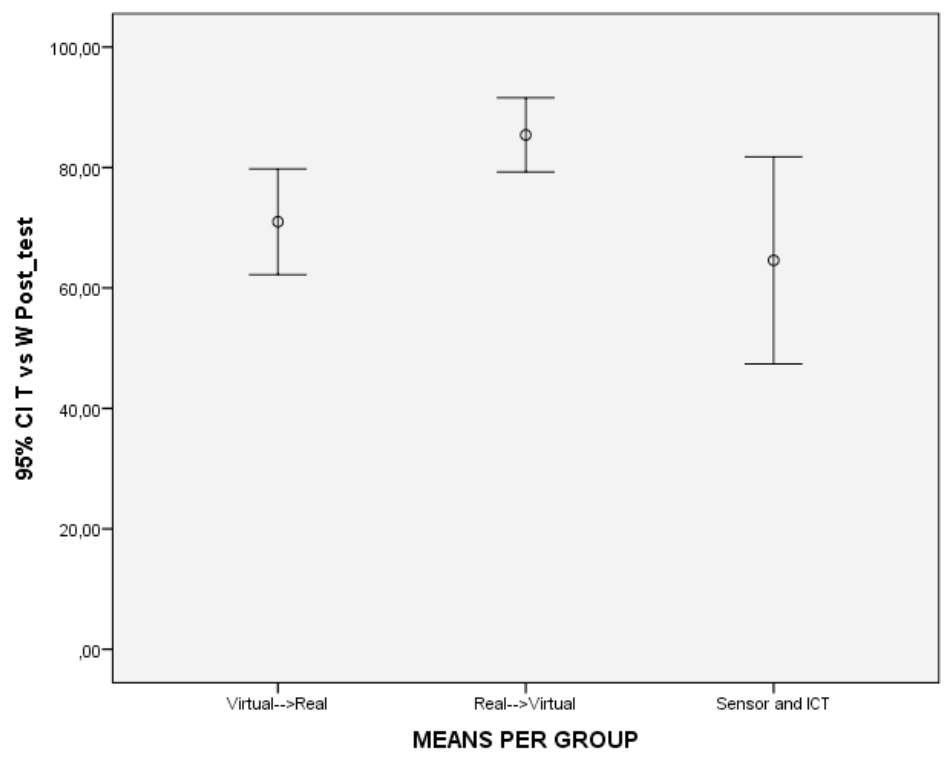

Fig. 2. Error chart for the participant groups in the research at post-test 


\section{Discussion and Conclusions}

The results of this research effort have shown that selecting to experiment in the orderof "real lab first to virtual lab later"has a better effect on learning, than when selecting the opposite experimentation order,when learning the behaviour of simple gravity pendulum. It also offers clearly better learning outcomes than when the exerciseinvolved sensors and data loggers. It would appear that, somehow, the greater abstraction offered by the suitably designed, virtual laboratory acts as a halfway step towards the formal abstraction, represented by the ultimate goal - the theoretical understanding.

Measurements have also confirmed that learners can use the lab equipment to work on both real and virtual lab somehow in parallel, and utilising simulations, and reallab equipment, and sensors and data loggers to enhance learners' conceptual development, thus making it an appropriate and contemporary tool for the teaching of pendulums. Furthermore, the results of the study revealed that the cyclical process of virtual to real or alternatively from real to virtual lab maintained learners' interest (in that it did not seem to be a straight repetition), enhancing their critical thinking and improving the learning process.

There is also an apparent need to expand the present research for the optimum order of real and virtual labs use in teaching, and investigate the relative merits of either strategy when teaching other Physics subjects. It is the expressed intention of the authors to persevere in this research direction.

\section{References}

[1] Gauld, C.(2005). Pendulums in the Physics Education Literature: A bibliography. In: Matthews, M., Gauld, C. \&Stinner, A.(eds.).The pendulum, pp. 505 - 526. Springer, Netherlands. https://doi.org/10.1007/1-4020-3526-8 32

[2] Cwudkova, L., Musilova, J.(2000). The Pendulum: A Stumbling Block of Secondary School Mechanics. Physics Education, 35(6), 428-435). https://doi.org/10.1088/00319120/35/6/309

[3] Galili, I., Sela, D. (2002). Pendulum activities in the Physics curriculum: Used and missed opportunities. In: Matthews, M.R. (Ed.), International Pendulum Project, Conferences Papers, vol. 2, pp. 189-203.The University of New South Wales, Sydney.

[4] Il-Ho Yang, Yong-Ju Kwon \&Jin-Woo Jeong. (2002). Effects of Students' Prior Knowledge on Scientific Reasoning in Solving Pendulum Task. In Matthews M.R. (Ed.), International Pendulum Project, Conferences Papers, vol.1, pp. 163-175. The University of New South Wales, Sydney.

[5] Koumaras, P.(2002).Using the Pendulum in the Education of Teachers. In: Matthews M.R. (Ed.), International Pendulum Project, Conferences Papers, vol. 2, pp. 205-219. The University of New South Wales, Sydney.

[6] Dossis, S., Koliopoulos, D.,(2005). The problem of timekeeping with the help of the simple pendulum: An Empirical Study of 14-15-year-old Greek School Students. In: M. Matthews (Ed.), 2nd International Pendulum Project, pp. 65-78. University of New South Wales, Sydney. 
Paper-The Effect of Switching the Order of Experimental Teaching in the Study of Simple Gravity...

[7] Dossis, S.,Koliopoulos, D.(2007). Comment les élèves du collège conçoivent le mouvement du pendule: une recherche empirique. Skholê, vol. Hors-série, 1, 41-51.

[8] Sumida, M., (2005). The public understanding of pendulum motion: From 5 to 88 years old. In: Matthews, M., Gauld, C., Stinner, A. (eds.)The Pendulum, pp. 465 - 484. Springer, Netherlands. https://doi.org/10.1007/1-4020-3526-8 29

[9] Inhelder, B., Piaget, J.(1958). The growth of logical thinking from childhood to adolescence. Routledge and Kegan Paul, London.

[10] Gil Perez, D., Carrascosa, J.(1985). Science learning as a conceptual and methodological change. European Journal of Science Education, 7(3), 231- 236.

[11] Bond, G.T.,(2002).Piaget and the Pendulum. In Matthews M.R. (Ed.), International Pendulum Project, Conferences Papers, vol. 1, pp. 121-129. Sydney: The University of New South Wales.

[12] Stafford, E.,(2002). What the pendulum can tell educators about children's scientific reasoning. In Matthews M.R. (Ed.), International Pendulum Project, Conferences Papers, vol.2, pp. 145-175, The University of New South Wales, Sydney.

[13] Edwardes, E.,(1997). The story of the pendulum clock. Altrincham: John Sherratt\& Son.

[14] Drake, S,(1990). The laws of pendulum and fall. In: Drake, S., (Ed.), Galileo: Pioneer Scientist. University of Toronto Press, Toronto.

[15] Drake, S.,(1996).Galileo at work. Dover Publications, New York.

[16] Boulos, P.,(2005).Newton's path to universal gravitation: the role of the pendulum. In: Matthews, M., Gauld, C. \&Stinner, A. (eds.), The pendulum, pp. 151-169. Springer, Netherlands https://doi.org/10.1007/1-4020-3526-8 12

[17] Emmerson, A.,(2002).Things are seldom what they seem -Christiaan Huygens, the pendulum and the cycloid. In: M. Matthews (Ed.), 2nd International Pendulum Project, pp. 79130. University of New South Wales, Sydney.

[18] Matthews, M., Gauld, C., Stinner, A. (eds.)., (2005). The pendulum, pp. 99-113, Springer, Netherlands.

[19] Psillos, D., Niedderer, H., (2002). Issues and Questions Regarding the Effectiveness of Labwork. In: Psillos, D., Niedderer, H. (eds.). Teaching and Learning in the Science Laboratory, pp. 21-20. Kluwer Academic Publishers, Netherlands.

[20] Choi, C., A., Gennaro, E., (1987). The effectiveness of using computer simulated experiments on junior high students' understanding of the volume displacement concept. Journal of Research in Science Teaching, 24(6), 539-552. https://doi.org/10.1002/tea.3660240604

[21] Mosterman, P. J. (1994). Student Perceptions of Learning in the Laboratory: Comparison of Industrially Situated VirtualLaboratories to Capstone Physical Laboratories.Journal of Engineering Education, 100(3), 540-573.

[22] Kocijancic, S.,O' Sullivan, C., (2004). Real or Virtual Laboratories in Science Teaching is this Actually a Dilemma? Informatics in Education, 3(2), 239-250.

[23] Wiliam, D. (2011)What is assessment for learning? Studies in Educational Evaluation, Vol. 37, pp. 3-14.

\section{Authors}

Charilaos A. Tsihouridis is a M.Sc., PhD holder and currently a Doctoral Research Student in the Department of Special Education, in the University of Thessaly, Volos, Greece. His research interests lie on the field of ICTs, experimental Physics and sciences in general. He has published an extensive number of articles on relevant issues and presented his research work in many conferences worldwide. 
Dennis Vavougios, is a PhD holder and a Professor of Physics and Science Education in the Department of Special Education in the University of Thessaly, Volos, Greece. His research interests include ICTs, and Science Education. He has participated and announced his work in a big number of conferences and published his work in relevant journals.

George S. Ioannidis, is a PhD holder, an Associate Professor and Head of Science Laboratory in the School of Education in the University of Patras, Greece. His research interests include ICTs in education, the study of sciences, and Physics. He has published an extensive number of articles and has participated in numerous conferences worldwide.

Article submitted 05 December 2016. Published as resubmitted by the authors 23 February 2017. 